\title{
Troglitazone reduces plasminogen activator inhibitor-1 expression and secretion in cultured human adipocytes
}

\author{
H. Gottschling-Zeller, K. Röhrig, H.Hauner \\ Diabetes Research Institute at the Heinrich-Heine-University Düsseldorf, Clinical Department, Düsseldorf, Germany
}

\section{Abstract}

Aims/hypothesis. Increased plasma plasminogen activator inhibitor-1 (PAI-1) concentrations are characteristic for subjects with insulin resistance and could contribute to the increased cardiovascular risk in this state. In this study, we investigated the effect of troglitazone, a ligand of the nuclear receptor peroxisome proliferator activated receptor- $\gamma$, on PAI-1 expression and secretion in human adipocytes.

Methods. We used two models: in vitro differentiated subcutaneous and omental adipocytes cultured under serum-free conditions and isolated subcutaneous and omental fat cells kept in suspension culture. Plasminogen activator inhibitor-1 protein was measured by ELISA, PAI-1 mRNA by a semiquantitative RTPCR technique.

Results. Exposure of in vitro differentiated subcutaneous adipocytes from young normal-weight females to $1 \mu \mathrm{g} / \mathrm{ml}$ troglitazone for $72 \mathrm{~h}$ caused a reduction of both PAI-1 secretion (by $29 \pm 5 \% ; p<0.01$ ) and
PAI-1 mRNA expression (by $26 \pm 3 \% ; p<0.05$ ). In cultures from severely obese subjects, troglitazone induced a decrease of PAI-1 antigen secretion from newly differentiated omental adipocytes by $49 \pm 8 \%$ $(p<0.01)$ and from subcutaneous adipocytes by $30 \pm 7 \%(p<0.05)$. Exposure of freshly isolated subcutaneous and omental adipocytes in suspension culture to troglitazone induced a similar reduction of PAI-1 concentration in the culture medium (by $35 \pm 11 \%, p<0.05$. and $33 \pm 8 \%, p<0.05$ compared with control, respectively).

Conclusion/interpretation. This study provides evidence that troglitazone reduces PAI- 1 production in human adipocytes, probably at the transcriptional level. This observation could point to a new beneficial effect of troglitazone, particularly in obese subjects, which could be associated with a reduced cardiovascular risk. [Diabetologia (2000) 43: 377-383]

Keywords Plasminogen activator inhibitor-1, troglitazone, human adipocytes, Type II diabetes, obesity.
Obesity is frequently associated with a cluster of cardiovascular risk factors that includes insulin resistance, impaired glucose tolerance or Type II (non-insulin-dependent) diabetes mellitus, high blood pressure, hypertriglyceridaemia and low HDL-cholester-

Received: 28 September 1999 and in revised form: 11 November 1999

Corresponding author: H. Hauner, MD, Diabetes Research Institute at the Heinrich-Heine-University Düsseldorf, Auf'm Hennekamp 65. D-40225 Düsseldorf, Germany

Abbreviations: PAI-1, Plasminogen activator inhibitor-1; PPAR- $\gamma$, peroxisome proliferator activated receptor. ol [1]. Among the multiple mechanisms which could explain the relation between insulin resistance and cardiovascular disease, disorders of the fibrinolytic system seem to play an important part [2]. The impairment of fibrinolysis in insulin resistance and Type II diabetes is characterized by increases in plasma plasminogen activator inhibitor (PAI-1) antigen and its activity [2]. Increased plasma concentrations of PAI-1 are observed particularly in subjects with an abdominal distribution of adipose tissue [3-5], but are also positively associated with other components of the insulin-resistance syndrome [5-8]. Although liver and endothelial cells are considered to be major sources of plasma PAI-1 $[9,10]$, recent stud- 
ies have shown that adipose tissue, especially in the visceral depot, produces substantial amounts of PAI1 and could contribute to the increased PAI-1 concentrations in obesity [11-15].

Thiazolidinediones such as troglitazone are new insulin sensitizing agents that have favourable effects on many components of the insulin-resistance syndrome, lowering not only plasma glucose but also hyperinsulinaemia and triglycerides and decreasing blood pressure [16-18]. Recently, it has been reported that treatment of a small group of Type II diabetic patients with troglitazone for 6 months significantly reduced plasma PAI-1 concentrations [19]. Moreover, another group showed that treatment of women with the polycystic ovary syndrome (PCOS) with troglitazone significantly decreased plasma PAI-1 protein concentration and activity [20]. Very recently, it has been shown that troglitazone and pioglitazone inhibit PAI-1 expression and secretion in human endothelial cells after TNF- $\alpha$ stimulation [21].

Irrespective of these observations, it is currently not known whether troglitazone affects PAI-1 production in human adipose tissue, the main site of thiazolidinedione action and a major source of increased plasma PAI-1 concentrations in the insulin-resistance syndrome. Therefore, it was the aim of this study to investigate the effect of troglitazone on PAI-1 expression and secretion in human adipocytes.

\section{Materials and methods}

Materials. Collagenase CLS type 1 was obtained from Worthington (Freehold, N.J., USA); human insulin and cortisol were kindly donated by Hoechst Marion Roussel (Frankfurt, Germany); gentamycin was purchased from Sigma (Munich, Germany); troglitazone was kindly donated by Sankyo (Tokyo, Japan); the PAI-1 ELISA kit was purchased from WAK Chemie (Hamburg, Germany); TRIzol, Superscript RT reverse transcriptase, random hexamers, Taq polymerase, PCR buffer, dCTP, dGTP, dTTP, dATP and culture media were obtained from Gibco (Berlin, Germany); all other chemicals were from Boehringer (Mannheim, Germany) or Merck (Darmstadt, Germany). Sterile plasticware for tissue culture was purchased from Flow Laboratories (Irvine, Scotland).

Subjects. Subcutaneous adipose tissue samples (10 to $80 \mathrm{~g}$ wet weight) were obtained from the mammary adipose tissue of ten young normal-weight women $\left(\mathrm{BMI}<26 \mathrm{~kg} / \mathrm{m}^{2}\right.$, age-range 19 to 40 years) undergoing surgical mammary reduction. In addition, we also collected abdominal subcutaneous and omental adipose tissue samples ( 2 to $15 \mathrm{~g}$ wet weight) from ten extremely obese people (BMI: $44.6 \pm 8.7 \mathrm{~kg} / \mathrm{m}^{2}$, age-range 26 to 52 years) who underwent vertical gastric banding for weight reduction. All subjects were of Caucasian origin and did not suffer from acute infection, cancer or any other consuming disease. Informed consent was obtained from all subjects. Tissue collection was approved by the ethical committee of the Heinrich-Heine-University Düsseldorf.

Isolation and culture of stromal cells. The adipose tissue samples were transported in DMEM/Ham's F-12 medium. The stromal cell fraction was isolated by collagenase digestion as described previously [22]. The isolated cells were suspended in DMEM/Ham's F-12 medium (vol/vol, 50:50), supplemented with $10 \%$ fetal calf serum. After cell adhesion for $16 \mathrm{~h}$ cultures were kept under serum-free, hormone-supplemented conditions to allow adipose differentiation [22]. During the 16-day culture period 40 to $70 \%$ of the stromal cells underwent morphological adipose differentiation. Cells were defined as adipocytes differentiated in vitro when their cytoplasma was completely filled with small or large lipid droplets which can be easily detected under the microscope. Cultures were then incubated with troglitazone $(0.1$ or $1 \mu \mathrm{g} / \mathrm{ml})$ for the times indicated.

Human adipocytes in suspension culture. Human adipose tissue samples were transported in DMEM/Ham's F-12 medium containing $4 \%$ BSA. Fat cells were isolated by collagenase digestion according a method reported previously [23] with some modifications to minimize traumatization of the fragile adipocytes. After enzymatic disaggregation of the tissue, the floating adipocyte layer was washed three times with PBS buffer containing $4 \%$ BSA. Finally, the fat-cell solution was filtered through a nylon mesh of $280 \mu \mathrm{m}$ pore size.

After isolation, the sizes and numbers of fat cells were determined in diluted aliquots. The assessment of mean fat-cell diameter was based on at least 150 cells from each adipose tissue sample. The mean fat-cell volume was calculated from the diameter.

The freshly isolated fat cells were incubated in DMEM/ Ham's F-12 medium containing 4\% BSA in the absence or presence of troglitazone ( 0.1 or $1 \mu \mathrm{g} / \mathrm{ml}$ final concentration) for $24 \mathrm{~h}$ at $37^{\circ} \mathrm{C}$ in a smoothly shaking waterbath at a dilution of $1: 10$.

For assessment of fat-cell viability, lactate dehydrogenase was assayed in the culture medium after $2 \mathrm{~h}, 6 \mathrm{~h}$ and $24 \mathrm{~h}$ of incubation. No statistically significant change of LDH activity was observed during the 24-h period (data not shown).

$R N A$ extraction. We prepared RNA from primary cultures and suspension culture according to a RNA isolation technique described previously [24]. Cells were harvested in TRIzol and $200 \mu \mathrm{l}$ chloroform was added to newly differentiated adipocytes per dish or $500 \mu \mathrm{l}$ to a sample of isolated fat cells, respectively. After centrifugation for $15 \mathrm{~min}$ at $12000 \mathrm{~g}$, the aqueous phase was mixed with an equal volume of isopropylalcohol. After $12 \mathrm{~h}$ at $-20^{\circ} \mathrm{C}$, the RNA was pelleted for $15 \mathrm{~min}$ at $10000 \mathrm{~g}$, redissolved in $\mathrm{LiCl}_{4}$, washed twice with $70 \%$ ethanol, dried and redissolved in $\mathrm{H}_{2} \mathrm{O}$. The purity of the RNA yield was verified by electrophoresis in a formaldehyde containing agarose gel.

cDNA generation and polymerase chain reaction (PCR). Total RNA was diluted to $0.2 \mu \mathrm{g} / \mu \mathrm{l}$ in $\mathrm{H}_{2} \mathrm{O}$ and 1 st strand cDNA was prepared using $5 \mu$ l of RNA, Superscript RT reverse transcriptase and random hexamers according to the instructions of the manufacturer. Then $2.5 \mu \mathrm{l}$ of cDNA and a PCR primer mix containing $2 \mathrm{U} \mathrm{Taq}$ polymerase in PCR buffer, $200 \mu \mathrm{mol} / 1$ of dCTP, dGTP, dTTP, dATP and $500 \mathrm{pmol} / \mathrm{l}$ of each primer were diluted in a $50 \mu \mathrm{l}$ volume and $50 \mu \mathrm{l}$ mineral oil were added. PCR condition was a denaturating step at $94^{\circ} \mathrm{C}$ for $2 \mathrm{~min}$ followed by 30 cycles of $94^{\circ} \mathrm{C}, 30 \mathrm{~s} ; 51^{\circ} \mathrm{C}, 30 \mathrm{~s} ; 72^{\circ} \mathrm{C}, 45 \mathrm{~s}$ for the detection of PAI- 1 mRNA. Polymerase chain reaction products were transferred on a $2 \%$ TBE-agarose gel, stained with ethidiumbromid and were analysed using the LumiAnalyst system from Boehringer (Mannheim, Germany).

For the semiquantificative analysis, two primer sets were used simultaneously in the same tube: one primer set was spe- 


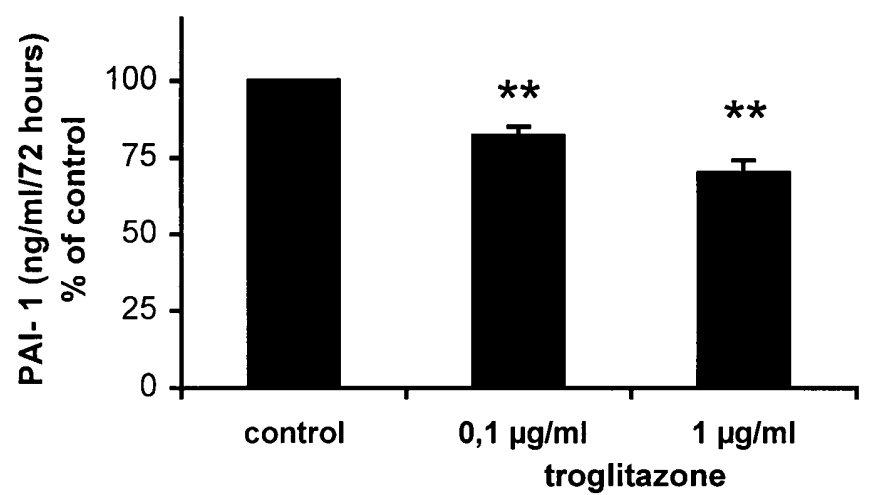

Fig. 1. Dose-dependent effect of troglitazone on PAI-1 protein release into the cultured medium of newly differentiated subcutaneous adipocytes within $72 \mathrm{~h}$. Data represent means \pm SEM of eight separate experiments with $1 \mu \mathrm{g} / \mathrm{ml}$ troglitazone (PAI-1 basal concentration in control cultures $57.1 \pm 6.9$ $\mathrm{ng} \cdot \mathrm{ml}^{-1} \cdot 72 \mathrm{~h}^{-1}$ ) and four separate experiments with $0.1 \mu \mathrm{g} /$ $\mathrm{ml}$ troglitazone (PAI-1 basal concentration in control cultures $\left.61.8 \pm 10.9 \mathrm{ng} \cdot \mathrm{ml}^{-1} \cdot 72 \mathrm{~h}^{-1}\right)$, respectively. Results are expressed as a per cent of the control value (defined as $100 \%$ ). $* * p<0.01$

cific for PAI-1 and the other specific for the transcription factor Sp1 which is ubiquitously expressed and was used as an internal specific standard [25]: human PAI-1 gene specific primers (301 bp): 5 ' GTG TTT CAG CAG GTG GCG C-3' sense; 5 '-CCG GAA CAG CCT GAA GAA GTG-3 ' antisense; Sp1 specific primers (231 bp): 5'-GAG AGT GGC TCA CAG CCT GTC-3' sense; 5'-GTT CAG AGC ATC AGA CCC CTG-3' antisense. The sequence of the PAI-1 transcript was confirmed using the ABI Prism BigDye Terminator Cycle Sequencing Ready Reaction Kit (Perkin Elmer, Weiterstadt, Germany) according to the instructions of the manufacturer.

Immunhistochemical staining of CD-31 and PAI-1 in newly differentiated adipocytes. To detect a possible contamination by endothelial cells, the stromal fraction from omental and subcutaneous adipose tissue was cultured on cell chamber slides (Becton Dickinson, Franklin Lakes, N.J., USA) for up to 16 days. Immunohistochemical analysis was carried out using a primary mouse monoclonal antibody against CD-31 (Dako, Carpentina, Calif., USA) and a primary sheep polyclonal antibody (Chemicon, Temecula, Calif., USA) directed against PAI-1. After washing with PBS, the newly differentiated fat cells were fixed with ethanol containing $10 \%$ methanol. Then, cell cultures were subjected to the protocol of Dako (LSAB Kit, Carpentina, Calif., USA). To determine the specificity of the immunostaining procedure, cells were also incubated in the absence of the primary antibody. Finally, the slides were counterstained with haematoxylin for $30 \mathrm{~s}$, rinsed with tap water, mounted in Entellan (Merck, Darmstadt, Germany) and examined using an EM109 microscope (Carl Zeiss, Jena, Germany). The specificity of the antibodies was also controlled by staining HUVEC cultures (obtained from Dr. P. Rösen from Diabetes Research Institute, Biochemical Department, Düsseldorf) using the same protocol.

Measurement of PAI-1 protein. The culture medium for the determination of PAI- 1 protein was stored at $-80^{\circ} \mathrm{C}$. We assayed PAI-1 protein using a commercially available specific enzyme-linked immunosorbent assay kit (ELISA, WAK-Chemie, Hamburg, Germany). The inter-assay and intra-assay variations were less than $10 \%$ and $5 \%$, respectively.

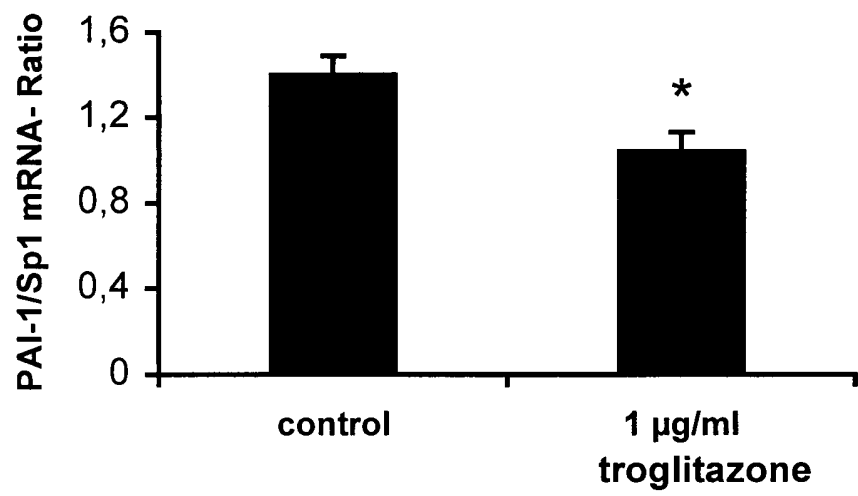

Fig. 2. Effect of a $72-\mathrm{h}$ exposure to $1 \mu \mathrm{g} / \mathrm{ml}$ troglitazone on PAI-1 mRNA expression in human adipocytes differentiated in vitro from the subcutaneous depot of lean women. Data represent means \pm SEM of three separate experiments. $* p<0.05$

Statistical analysis. Results are expressed as means \pm SEM. Differences between groups were tested using two-tailed Student's $t$-test for paired data. Differences with $p$ less than 0.05 were considered as significant.

\section{Results}

Effects of troglitazone on PAI-1 secretion and expression by newly differentiated adipocytes. Basal PAI-1 secretion from subcutaneous adipocytes differentiated in vitro was $57.1 \pm 7.0 \mathrm{ng} \cdot \mathrm{ml}^{-1} \cdot 72 \mathrm{~h}^{-1}$. A positive correlation between the percentage of differentiated cells and the concentration of PAI-1 released was found $(r=0.97 ; p<0.05)$. When $1 \mu \mathrm{g} / \mathrm{ml}$ troglitazone was added to the culture medium of subcutaneous adipocytes differentiated in vitro from eight subjects, PAI-1 secretion was reduced by $29 \pm 5 \%$ compared with control cultures $(p<0.01)$ (Fig. 1). A smaller, but also statistically significant inhibitory effect was seen in the presence of $0.1 \mu \mathrm{g} / \mathrm{ml}$ troglitazone (by $18 \pm 3 \%, p<0.01$ ) (Fig. 1). Lower concentrations of troglitazone did not statistically significantly affect PAI-1 secretion (data not shown). Exposure of differentiated subcutaneous adipocytes from three subjects to $1 \mu \mathrm{g} / \mathrm{ml}$ troglitazone for different periods of time caused a decrease of PAI-1 secretion into the culture medium: by $21 \pm 6 \%$, NS, after 2 hours; by $11 \pm 1 \%$, $p<0.05$. after $6 \mathrm{~h}$; by $18 \pm 1 \%$, NS, after $24 \mathrm{~h}$; by $17 \pm 12 \%$, NS, after $48 \mathrm{~h}$ and by $28 \pm 5 \%, p<0.05$. after $72 \mathrm{~h}$ of incubation, respectively.

To find out whether troglitazone affects PAI-1 production at the mRNA expression, we studied the effect of the compound on steady-state PAI-1 mRNA expression in newly differentiated subcutaneous adipocytes from three subjects. A 72-h incubation with $1 \mu \mathrm{g} / \mathrm{ml}$ troglitazone caused a reduction in the expression of PAI- 1 mRNA by $26 \pm 3 \%(p<0.05)$ (Fig. 2$)$.

To assess the possible role of obesity and of the anatomical origin of the tissue on the effect of troglitaz- 

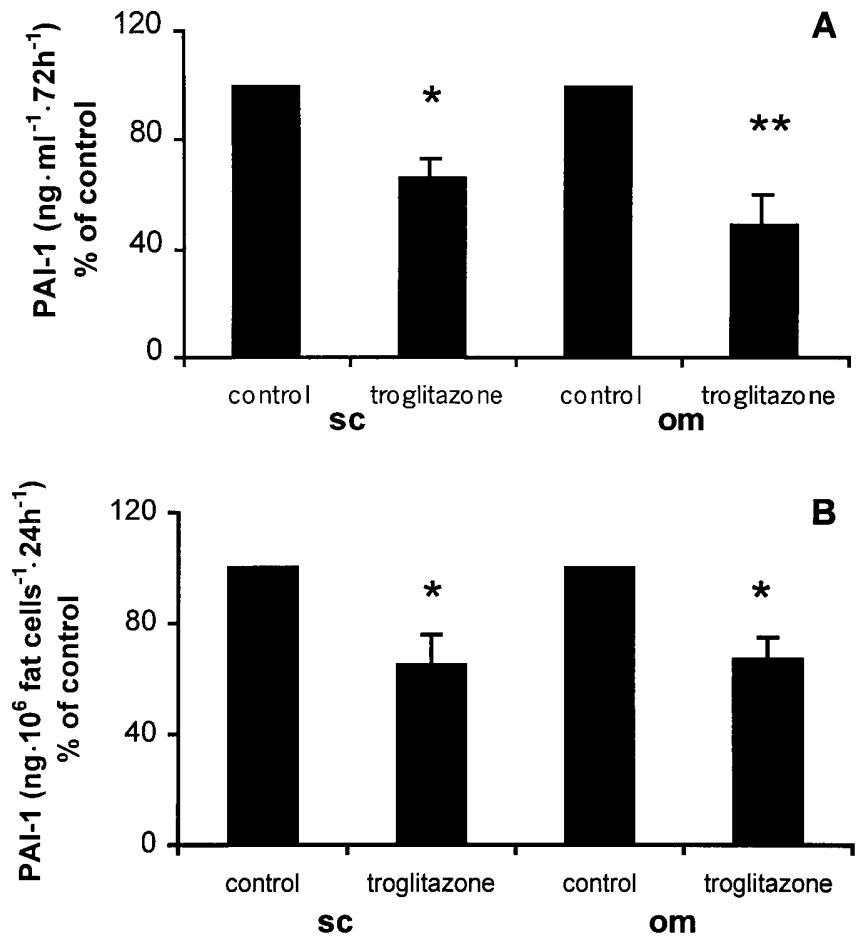

Fig. 3 A, B. Effect of $1 \mu \mathrm{g} / \mathrm{ml}$ troglitazone on PAI- 1 secretion from cultured subcutaneous and omental adipocytes. A Subcutaneous (sc) and omental (om) adipocytes differentiated in vitro exposed to $1 \mu \mathrm{g} / \mathrm{ml}$ troglitazone for $72 \mathrm{~h}$. Data represent means \pm SEM of three separate experiments and are expressed as a per cent of the control value $(100 \%)$. B Isolated subcutaneous (sc) and omental (om) fat cells in suspension culture exposed to $1 \mu \mathrm{g} / \mathrm{ml}$ troglitazone for $24 \mathrm{~h}$. Data represent means \pm SEM of six separate experiments and are expressed as a per cent of the control value $(100 \%)$. * $p<0.05$. ** $p<0.01$

one on PAI-1 secretion, we additionally investigated the effect of the thiazolidinedione on PAI-1 secretion from abdominal subcutaneous and omental adipocytes differentiated in vitro in paired samples from four extremely obese subjects. The reduction of PAI-1 secretion after an exposure to $1 \mu \mathrm{g} / \mathrm{ml}$ troglitazone for $72 \mathrm{~h}$ was greater in cultures of omental adipocytes (by $49 \pm 8 \% ; p<0.01$ compared with control cultures) than in cultures of subcutaneous adipocytes (by $30 \pm 7 \% ; p<0.05$ compared with control cultures) (Fig. 3A). The relative reduction by troglitazone was, however, not statistically different between the two depots.

Human adipocytes that are differentiated in vitro are a valuable model to study the long-term regulation of adipose tissue metabolism. Because the total stromal cell fraction is cultured, it cannot, however, be excluded that other cell-types present in adipose tissue contribute to the effect we observed. Therefore, we did additional experiments for clarification. One approach was to determine a possible contamination of the stromal fraction by endothelial cells. Previous immunohistochemical studies had already shown that the subcutaneous stromal fraction is es- sentially free of endothelial cells [22]. Immunohistochemical staining using a monoclonal antibody against CD-31 was negative in all cultures obtained from omental as well as from subcutaneous abdominal adipose tissue, arguing against a relevant contamination by endothelial cells. Furthermore, staining of the cultures with a polyclonal antibody against PAI-1 revealed a positive reaction only in differentiated adipocytes (data not shown).

Effect of troglitazone on PAI-1 secretion by isolated adipocytes kept in suspension culture. To obtain further evidence that the effect of troglitazone is specifically exerted in adipocytes, we studied the effect of the compound in an in vitro model of isolated fat cells maintained in suspension culture which was free of other contaminating cell-types. The basal rate of PAI-1 antigen secretion into the culture medium was lower in isolated subcutaneous abdominal fat cells than in isolated omental adipocytes $(82.2 \pm 33.4$ vs $183.5 \pm 95.6 \mathrm{ng} \cdot 10^{6}$ fat cells $^{-1} \cdot 24 \mathrm{~h}^{-1} ; n=6$; $p<0.05)$. To further investigate a possible depot-specific difference in the inhibitory effect of troglitazone on PAI-1 secretion, we incubated isolated subcutaneous and omental adipocytes in paired samples from six extremely obese subjects with $1 \mu \mathrm{g} / \mathrm{ml}$ troglitazone for $24 \mathrm{~h}$. This treatment caused a similar decrease of PAI-1 protein concentration in the culture medium from both subcutaneous (by $35 \pm 11 \%, p<0.05$ ) and omental adipocytes (by $33 \pm 8 \%, p<0.05$ ) (Fig 3B). A moderate, but not significant decrease of PAI-1 secretion from abdominal subcutaneous adipocytes was already detectable at a concentration of $0.1 \mu \mathrm{g} / \mathrm{ml}$ troglitazone (by $26 \pm 8 \% ; n=3$; NS).

We also studied the effect of troglitazone on PAI1 mRNA expression in isolated abdominal subcutaneous fat cells from three subjects. A 24-h incubation with $1 \mu \mathrm{g} / \mathrm{ml}$ troglitazone caused only a small but not significant reduction in the expression of PAI1 mRNA (by $11 \pm 5 \%$, NS).

\section{Discussion}

In this study, we analysed the effect of troglitazone on PAI-1 production in human fat cells using two in vitro models: newly differentiated subcutaneous and omental adipocytes cultured under serum-free, hormone-supplemented conditions and freshly isolated adipocytes from subcutaneous and omental adipose tissue maintained for $24 \mathrm{~h}$ in suspension culture. The first model has the advantage of allowing the investigation of long-term effects under stable conditions and providing a reliable preparation of RNA. It should be noted that despite the limited percentage of full differentiation the stromal cell fraction is a homogenous population according to morphological criteria, i. e. there is an accumulation of very small lip- 
id inclusions [26]. The second model is characterized by an almost pure preparation of fat cells but is not so ideal for long-term tissue culture. Both methods gave very similar results clearly indicating that troglitazone reduces PAI-1 expression and secretion in cultured human adipocytes.

Increased plasma PAI-1 concentrations have been reported to be characteristic for the insulin-resistance syndrome $[2,13,14]$, although the mechanisms linking the two conditions are still not clear. One plausible explanation is that an increased adipose expression of TNF- $\alpha$ and TGF- $\beta$ could mediate the link between insulin resistance and increased PAI-1 in obesity [27]. The clinical relevance of this association is unambigous, as increased plasma concentrations of PAI-1 have been found to be a cardiovascular risk factor in epidemiological studies [2, 7]. Therefore it is important to establish how drugs that are advocated for the treatment of insulin resistance affect PAI1 concentrations.

Thiazolidinediones are activators of peroxisome proliferator activated receptor (PPAR- $\gamma$ ) a nuclear receptor [28], and are a new class of oral hypoglycaemic drugs that enhance the insulin action. These agents were found to reduce insulin resistance in obese and Type II diabetic subjects by increasing insulin-dependent glucose uptake and reducing hepatic glucose output [18], thereby reducing hyperglycaemia, raised insulin and triglyceride concentrations and hypertension [16-18]. Recently, a beneficial effect of troglitazone, a member of the class of thiazolidinediones, has been shown on both impaired fibrinolysis and activated coagulation associated with Type II diabetes [19]. In that study, treatment of diabetic patients with $200-600 \mathrm{mg} /$ day troglitazone for 6 months led to a statistically significant decrease of plasma PAI-1 concentrations [19]. Another recent study investigated the effect of troglitazone in obese women with polycystic ovary syndrome, who were characterized by defects in insulin action, insulin secretion, ovarian steroidogenesis and fibrinolysis. Treatment with troglitazone for 12 weeks also caused a decrease in plasma PAI-1 protein and activity [20]. Despite these clear-cut effects, these clinical studies cannot show which sites of PAI-1 production are involved and which mechanisms are responsible for the decrease of PAI-1 by troglitazone treatment.

Recent studies suggested that human adipocytes are an important source of PAI-1 [13, 14]. Increased circulating PAI-1 concentrations were associated with increased fat-cell size and fat mass in humans indicating that adipose tissue contributes to the increased PAI-1-concentrations found in obesity [14]. Our results clearly indicate that the decrease in PAI-1 concentrations after treatment with troglitazone is at least in part due to a suppression of PAI-1 production by adipocytes.
In newly differentiated adipocytes, the inhibitory effect of troglitazone on PAI-1 secretion was at maximum only after $72 \mathrm{~h}$. The first statistically significant reduction of PAI-1 release was, however, already observed after a 6-h exposure to the compound. In freshly isolated adipocytes in suspension culture the relative inhibitory effect of troglitazone was similar in both subcutaneous and omental adipocytes, although the absolute decrease in PAI-1 secretion was greater in omental fat cells due to their greater secretory rate $[13,14]$. In cultures of differentiated adipocytes from omental adipose tissue the down-regulation of PAI-1 release was moderately more pronounced than in cultures of the stromal fraction from subcutaneous adipose tissue, but this small difference was not statistically significant. Note even in abdominal obesity most of PAI-1 secretion is from subcutaneous fat cells because of the much larger tissue mass compared with the omental depots.

The results of our experiments also indicate that the reduction of PAI-1 expression and secretion by troglitazone is not due to effects on other cell-types. Cultures of the stromal cell fraction from both adipose tissue depots were free of contamination by endothelial cells, which are also a potential source of PAI-1 [10]. Additional immunohistochemical experiments done in this study further argue against a statistically significant contamination by endothelial cells in cultures from subcutaneous and omental adipose tissue. Although it cannot be completely excluded that other possibly contaminating cell-types such as smooth muscle cells could contribute to the PAI-1 release of the cultures, their relative contribution is probably rather low.

It was recently reported that exposure of TNF- $\alpha$ stimulated vascular endothelial cells to thiazolidindiones for $24 \mathrm{~h}$ resulted in an inhibition of PAI-1 expression and secretion possibly through a PPAR- $\gamma$ mediated mechanism, whereas basal secretion was not statistically significantly reduced [21]. The PPAR- $\gamma$, the cellular target of troglitazone is expressed in a relative adipose-selective fashion in both rodents and humans, but is also expressed in a variety of other tissues [29]. In another recent study PPAR- $\gamma$ activation in human endothelial cells was followed by an increased expression of PAI-1 and it was hypothesized from this in vitro study that PPAR $-\gamma$ acts as a potential mediator of vascular disease [30]. In our model of adipocytes differentiated in vitro, PPAR- $\gamma$ expression is already up-regulated. Under these conditions, PPAR- $\gamma$ mRNA expression is only moderately modulated by troglitazone and there is no other evidence that even addition of troglitazone for $72 \mathrm{~h}$ significantly affects the differentiation state (M. Birgel, personal communicationn).

Recent studies on the depot-related expression of PPAR- $\gamma$ showed a lower expression in visceral adipose tissue in lean and moderately overweight sub- 
jects, whereas in obese patients, PPAR- $\gamma$ mRNA expression was similar in the two depots [31]. This possible weight-dependent difference in PPAR- $\gamma$-expression is not reflected by a difference in the potential of troglitazone to suppress PAI-1 production according to our results. In another study, a consistent depot-specific difference in PPAR- $\gamma$ mRNA expression between isolated human subcutaneous and omental adipocytes could be not shown [32].

The results of our study show that troglitazone reduces PAI-1 production in cultured human adipocytes, probably at the transcriptional level. This observation could help to explain the beneficial effect of troglitazone on plasma PAI-1 concentrations reported in clinical studies. This observation could be another mechanism, by which troglitazone can reduce the increased cardiovascular risk of patients with the insulin-resistance syndrome.

Acknowledgements. We wish to thank Dr. B. Husemann and his team from the Surgical Department of the Dominikus Hospital, Düsseldorf-Heerdt, and Dr. R. Olbrisch and his team from the Department of Plastic Surgery at the Florence Nightingale Hospital Düsseldorf-Kaiserswerth for their support in obtaining adipose tissue samples. The partial financial support by Sankyo Europe, Düsseldorf, is gratefully acknowledged.

\section{References}

1. Kissebah AH, Freedman DS, Peiris AN (1989) Health risks of obesity. Med Clin North Am 73: 111-138

2. Juhan-Vague I, Alessi MC (1997) PAI-1, obesity, insulin resistance and risk of cardiovascular events. Thromb Haemost 78: 656-660

3. De Pergola G, De Mitrio V, Giorgino F et al. (1997) Increase in both pro-thrombotic and anti-thrombotic factors in obese premenopausal women: relationship with body fat distribution. Int J Obes Relat Metab Disord 21: 527-535

4. Janand-Delenne B, Chagnaud C, Raccah D, Alessi MC, Juhan-Vague I, Vague P (1998) Visceral fat as a main determinant of plasminogen activator inhibitor 1 level in women. Int J Obes Relat Metab Disord 22: 312-317

5. Vague P, Juhan-Vague I, Chabert V, Alessi MC, Atlan C (1989) Fat distribution and plasminogen activator inhibitor activity in nondiabetic obese women. Metabolism 38: 913-915

6. Juhan-Vague I, Alessi MC, Vague P (1996) Thrombogenic and fibrinolytic factors and cardiovascular risk in non-insulin-dependent diabetes mellitus. Ann Med 28: 371-380

7. Juhan-Vague I, Pyke SDM, Alessi MC, Jespersen J, Haverkate F, Thompson SG on behalf of the ECAT Study Group (1996) Fibrinolytic factors and the risk of myocardial infarction or sudden death in patients with angina pectoris. Circulation 94: 2057-2063

8. McGill JB, Schneider DJ, Arfken CL, Lucore CL, Sobel BE (1994) Factors responsible for impaired fibrinolysis in obese subjects and NIDDM patients. Diabetes 43: 104-109

9. Schneider DJ, Sobel BE (1991) Augmentation of synthesis of plasminogen activator inhibitor type 1 by insulin and insulin-like growth factor type I: Implications for vascular disease in hyperinsulinemic states. Proc Natl Acad Sci USA 88: 9959-9963
10. van Hingsberg VW, Kooistra T, van der Berg EA, Princen HM, Fiers W, Emeis JJ (1988) Tumor necrosis factor increases the production of plasminogen activator inhibitor in human endothelial cells in vitro and in rats in vivo. Blood 72: $1467-1473$

11. Lundgren $\mathrm{CH}$, Brown SL, Nordt TK, Sobel BE, Fujii S (1996) Elaboration of type-1 plasminogen activator inhibitor from adipocytes. a potential pathogenic link between obesity and cardiovascular disease. Circulation 93: 106-110

12. Samad F, Yamamoto K, Loskutoff DJ (1996) Distribution and regulation of plasminogen activator inhibitor-1 in murine adipose tissue in vivo. Induction by tumor necrosis factor- $\alpha$ and lipopolysaccaride. J Clin Invest 97: 37-46

13. Alessi MC, Peiretti F, Morange P, Henry M, Nalbone G, Juhan-Vague I (1997) Production of plasminogen activator inhibitor 1 by human adipose tissue. Possible link between visceral fat accumulation and vascular disease. Diabetes 46: 860-867

14. Eriksson P, Reynisdottir S, Lönnqvist F, Stemme V, Hamsten A, Arner P (1998) Adipose tissue secretion of plasminogen activator inhibitor-1 in non-obese and obese individuals. Diabetologia 41: 65-71

15. Shimomura I, Funahashi T, Takahashi M et al. (1996) Enhanced expression of PAI-1 in visceral fat: possible contributor to vascular disease in obesity. Nat Med 2: 800-803

16. Nolan JJ, Ludvik B, Beerdsen P, Joyce M, Olefsky J (1994) Improvement in glucose tolerance and insulin resistance in obese subjects treated with troglitazone. N Engl J Med 331: 1188-1193

17. Kumar S, Boulton AJM, Beck-Nielsen $\mathrm{H}$ et al. for the Troglitazone study group (1996) Troglitazone, an insulin action enhancer, improves metabolic control in NIDDM patients. Diabetologia 39: 701-709

18. Saltiel AR, Olefsky J (1996) Thiazolidinediones in the treatment of insulin resistance and type II diabetes. Diabetes 45: 1661-1669

19. Fonseca VA, Reynolds T, Hemphill D et al. (1998) Effect of troglitazone on fibrinolysis and activated coagulation in patients with non-insulin-dependent diabetes mellitus. J Diabetes Complications 12: 181-186

20. Ehrmann DA, Schneider DJ, Sobel BE et al. (1997) Troglitazone improves defects in insulin action, insulin secretion, ovarian steroidogenesis, and fibrinolysis in women with polycystic ovary syndrome. J Clin Endocrinol Metab 82: 2108-2116

21. Kato K, Satoh H, Endo Y et al. (1999) Thiazolidinediones down-regulate plasminogen activator inhibitor type 1 expression in human vascular endothelial cells:a possible role for PPAR $\gamma$ in endothelial function. Biochem Biophys Res Commun 258: 431-435

22. Hauner H, Entenmann G, Wabitsch M et al. (1989) Promoting effects of glucocorticoids on the differentiation of human adipocyte precursor cells cultured in a chemically defined medium. J Clin Invest 84: 1663-1670

23. Rodbell M (1964) Metabolism of isolated fat cell I. Effects of hormones on glucose metabolism and lipolysis. J Biol Chem 239: 375-380

24. Chomczynsky P, Sacchi N (1987) Single-step method for isolation by acid guanidinium thiocyanate-phenol-chloroform extraction. Anal Biochem 162: 156-159

25. Wabitsch M, Jensen PB, Blum WF et al. (1996) Insulin and cortisol promote leptin production in cultures human fat cells. Diabetes 45: 1435-1438

26. Entenmann G, Junger E, Gries FA, Hauner H (1994) Morphological characterization of human preadipocytes during in vitro adipoconversion under the control of insulin and cortisol. In: Ditschuneit H, Gries FA, Hauner H, Schu- 
sdziarra V, Wechsler JC (eds) Obesity in Europe 1993. John Libbey, London, pp 59-64

27. Samad F, Uysal KT, Wiebrock SM, Pandey M, Hotamisligil GS, Loskutoff DJ (1999) Tumor necrosis factor $\alpha$ is a key component in the obesity-link elevation of plasminogen activator inhibitor 1. Proc Natl Acad Sci USA 96: 6902-6907

28. Spiegelman BM (1998) PPAR- $\gamma$ : adipogenic regulator and thiazolidinedione receptor. Diabetes 47: 507-514

29. Auboeuf D, Rieusset J, Fajas L et al. (1997) Tissue distribution and quantification of the expression of mRNAs of peroxisome proliferator-activated receptors and liver $\mathrm{X}$ receptor- $\alpha$ in humans. No alteration in adipose tissue of obese and NIDDM patients. Diabetes 46: 1319-1327
30. Marx N, Bourcier T, Sokhova GK, Libby P, Plutzky J (1999) PPARgamma activation in human endothelial cells increases plasminogen activator inhibitor type-1 expression:PPARgamma as a potential mediator in vascular disease. Arterioscler Thromb Vasc Biol 19: 546-551

31. Lefebvre AM, Laville M, Vega N et al. (1998) Depot-specific differences in adipose tissue gene expression in lean and obese subjects. Diabetes 47: 98-103

32. Montague CT, Prins JB, Sanders L et al. (1998) Depot-related gene expression in human subcutaneous and omental adipocytes. Diabetes 47: 1384-1391 